\title{
PPGLinC
}

\section{EVIDÊNCIAS SOCIOLINGUÍSTICAS SOBRE OS USOS DO IMPERATIVO NO INTERIOR DA BAHIA ${ }^{1}$}

\author{
SOCIOLINGUISTIC EVIDENCE ABOUT THE USES OF \\ IMPERATIVE MOOD IN THE COUNTRYSIDE OF BAHIA
}

\author{
Lanuza Lima Santos² \\ Instituto Federal da Bahia
}

\begin{abstract}
Resumo: Este artigo analisa o uso variável do modo imperativo no português popular da Bahia, fundamentado no enquadramento teórico-metodológico da Sociolinguística Variacionista (WEINREICH; LABOV; HERZOG 2006 [1968]; LABOV, 2008 [1972]). O trabalho apresenta a alternância entre formas morfologicamente associadas ao indicativo (canta/não canta) e ao subjuntivo (cante/não cante) na expressão do modo imperativo em dados de fala de comunidades rurais da Bahia (Santo Antônio de Jesus, Poções, Barra e Bananal, Cinzento, Sapé e Helvécia). A análise quantitativa aponta a prevalência das formas do indicativo (canta) nessas comunidades. Esse resultado amplia o conhecimento acerca dos falares da Bahia e abre novas perspectivas de investigação acerca das isoglossas do imperativo ao apontar a complexidade da distribuição do fenômeno no estado.
\end{abstract}

Palavras-Chave: Modo imperativo; Português popular da Bahia; Variação sociolinguística.

1 Os dados apresentados neste artigo compõem um recorte do estudo realizado pela autora em tese de doutoramento (PPGLINC-UFBA) em 2016.

2 lanuzalima@gmail.com 
Abstract: This article analyses the variable use of imperative mood characterized by the shift in verb forms morphologically associated with the indicative (canta/não canta) and the subjunctive (cante/não cante) in Popular Portuguese of Bahia based on the theoretical-methodological framework of Variationist Sociolinguistics (WEINREICH; LABOV; HERZOG 2006 [1968]; LABOV, 2008 [1972]). This paper aims to present the variable expression of the imperative mood in the Popular Portuguese of rural communities of Bahia (Santo Antônio de Jesus, Poções, Barra e Bananal, Cinzento, Sapé e Helvécia). The quantitative analyses indicate the prevalence of the indicative forms (canta) among these communities. This result improves the knowledge about Bahia's speeches, opening to new perspectives about the imperative isoglosses insofar as It points out the complexity of the phenomenon distribution in Bahia.

Keywords: Imperative mood; Popular Portuguese of Bahia; Variationist Sociolinguistic.

\section{INTRODUÇÃO}

A expressão variável do imperativo no português caracteriza-se pela alternância entre formas morfologicamente associadas ao modo indicativo (canta/não canta) e ao modo subjuntivo (cante/não cante). No território brasileiro, tal variação configura uma linha dialetológica que opõe tendências de emprego do indicativo, presentes das regiões Sul, Sudeste e Centro Oeste (SCHERRE et alii, 2007), ao padrão do subjuntivo, comumente associado à região Nordeste SCHERRE et alii, 2007; OLIVEIRA, 2017).

Embora muitas análises tenham sido empreendidas sobre o tema, de modo geral, os estudos associam a Bahia à prevalência das variantes do subjuntivo (cante) (SAMPAIO, 2001; SCHERRE, 2007; ALVES, 2008; OLIVEIRA, 2017). A nossa investigação acerca do tema aponta um caráter sensivelmente diferenciado em relação às variedades populares rurais, para as quais dados empíricos revelam a predominância de um padrão indicativo (canta).

Assim, o objetivo precípuo deste artigo é apresentar um panorama das formas de expressão do imperativo no português popular de comunidades rurais da Bahia (variantes indicativas e subjuntivas). Os dados aqui apresentados integram o conjunto de corpora do Português Popular do Estado da Bahia, coletados e organizados pelo Projeto Vertentes (UFBA). Neste artigo, serão tratados especificamente os dados das variedades rurais estudadas, as 
comunidades remanescentes de quilombos (Sapé, Cinzento, Helvécia e Rio de Contas), também designadas comunidades afro-brasileiras, e as comunidades não marcadas etnicamente do interior do estado (Poções e Santo Antônio de Jesus).

\section{O IMPERATIVO NO PORTUGUÊS BRASILEIRO}

O imperativo, especializado na expressão da modalidade deôntica, é, conforme Oliveira (2003), o modo verbal pelo qual o falante expressa uma atitude diretiva em relação a um interlocutor, no intento de impelir-lhe um comportamento (verbal ou não verbal). Sua caracterização, conforme os diferentes níveis de análise da língua, pode ser sintetizada conforme o Quadro 1:

Quadro 1: Caracterização do modo verbal imperativo conforme os diferentes níveis de análise da língua

\begin{tabular}{|l|l|}
\hline NÍVEL DE ANÁLISE & \multicolumn{1}{c|}{ CARACTERIZAÇÃO } \\
\hline Morfológico & $\begin{array}{l}\text { possui morfologia não exclusiva, derivada dos modos } \\
\text { indicativo e subjuntivo; }\end{array}$ \\
\hline Semântico & $\begin{array}{l}\text { tem seu valor semântico associado a um ato diretivo de fala } \\
\text { que varia quanto ao teor impositivo e ao controle exercido } \\
\text { pelo locutor (ordens, exortação, pedidos, súplicas...); }\end{array}$ \\
\hline Sintático & $\begin{array}{l}\text { acontece em sentenças absolutas, principais ou } \\
\text { coordenadas; apresenta, em geral, sujeito superficial nulo; } \\
\text { permite, ao contrário das sentenças indicativas, a presença } \\
\text { do vocativo; }\end{array}$ \\
\hline Pragmático & $\begin{array}{l}\text { intenta exercer um comportamento sobre o ouvinte, de } \\
\text { maneira que a condição da interação entre os locutores, } \\
\text { reais ou virtuais, e a relação com o contexto são } \\
\text { imprescindíveis; }\end{array}$ \\
\hline Fonológico & possui padrão entoacional descendente. \\
\hline
\end{tabular}

Fonte: Elaborado pela autora.

Embora seja caracterizado em diferentes níveis, gramáticas normativas (CUNHA; CINTRA, 2002; BECHARA, 2002; ROCHA LIMA, 2003) costumam

3 A presença do sujeito é passível de ambiguidade na leitura imperativa. 
descrever o modo imperativo a partir de uma delimitação exclusivamente morfológica e pragmática. Segundo Rocha Lima (2003), o imperativo é empregado na direção a um ou mais interlocutores a fim de manifestar uma atitude que queremos que execute(m). Ao lado de sua função eminentemente discursiva, algumas gramáticas se debruçam em explicar a constituição morfológica do imperativo em português (CUNHA; CINTRA, 2002; ROCHA LIMA, 2003), destacando, por um lado, a existência de duas formas básicas, a afirmativa e a negativa, e, por outro, sua constituição mista, derivada das formas do presente do indicativo e do subjuntivo, conforme Quadro 2.

Quadro 2: Formação do modo imperativo na língua portuguesa conforme a prescrição gramatical

\begin{tabular}{|c|c|c|c|}
\hline $\begin{array}{c}\text { PRESENTE DO } \\
\text { INDICATIVO }\end{array}$ & $\begin{array}{l}\text { PRESENTE DO } \\
\text { SUBJUNTIVO }\end{array}$ & IMPERATIVO AFIRMATIVO & IMPERATIVO NEGATIVO \\
\hline eu falo & eu fale & & \\
\hline tu falas & tu fales & fala $(t u)$ & não fales (tu) \\
\hline você fala & você fale & fale (você) & não fale (você) \\
\hline nós falamos & nós falemos & falemos (nós) & não falemos (nós) \\
\hline vós falais & vós faleis & falai (vós) & não faleis (vós) \\
\hline vocês falam & vocês falem & falem (vocês) & não falem (vocês) \\
\hline
\end{tabular}

Fonte: Adaptado de Cunha e Cintra (2002)

A fim de evidenciar as imprecisões do modelo normativo em relação aos usos efetivamente observados no português contemporâneo, descrevemos, a seguir, aspectos variáveis do fenômeno. Para tanto, partimos da diferenciação entre as variedades europeia e nacional do idioma (cf. Quadro 3). 
Quadro 3: O uso do imperativo no português europeu e no português brasileiro

\begin{tabular}{|c|c|}
\hline $\begin{array}{l}\text { VARIEDADE } \\
\text { NACIONAL }\end{array}$ & CARACTERIZAÇÃO \\
\hline $\begin{array}{l}\text { Português } \\
\text { europeu: }\end{array}$ & $\begin{array}{l}\text { - Usos das formas imperativas em distribuição complementar; } \\
\text { - Formas usadas conforme o tipo de interação entre falante e } \\
\text { interlocutor: } \\
\Rightarrow \text { imperativo de } 2^{\underline{a}} \text { pessoa (derivado do indicativo canta/não } \\
\text { cantes) usado com o pronome tu em situações de } \\
\text { distanciamento] [+ intimidade] } \\
\Rightarrow \text { imperativo de } 3^{\underline{a}} \text { pessoa (cante/não cante) com pronome você em } \\
\text { situações [+ distanciamento] [- intimidade] (OLIVEIRA, 2003). }\end{array}$ \\
\hline $\begin{array}{l}\text { Português } \\
\text { brasileiro: }\end{array}$ & $\begin{array}{l}\text { - Variação linguística entre as formas derivadas do indicativo } \\
\text { diretamente negadas (canta/não canta) e as formas derivadas do } \\
\text { subjuntivo (cante/não cante). } \\
\text { - variação de caráter diatópico que diferencia as regiões Nordeste } \\
\text { e Sul, Sudeste e Centro-Oeste (SCHERRE, 2007), com indícios de } \\
\text { oposição entre realizações rurais e urbanas (SANTOS, 2016; } \\
\text { BONFÁ; PINTO; LUIZ; 1997). }\end{array}$ \\
\hline
\end{tabular}

Em contraste com o padrão normativo e com as formas empregadas em Portugal, evidencia-se, nos usos da do português no Brasil, a ausência da forma negativa de segunda pessoa do singular (não cantes) e a inexistência das formas da segunda pessoa do plural (cantai e não canteis). Além disso, a distribuição geográfica dos estudos sobre o tema revela o contraste entre o Sul e o Norte do país. Essa distribuição encontra-se ilustrada, na Figura 1. 
Figura 1: Usos do modo imperativo nas diferentes regiões brasileiras ${ }^{4}$

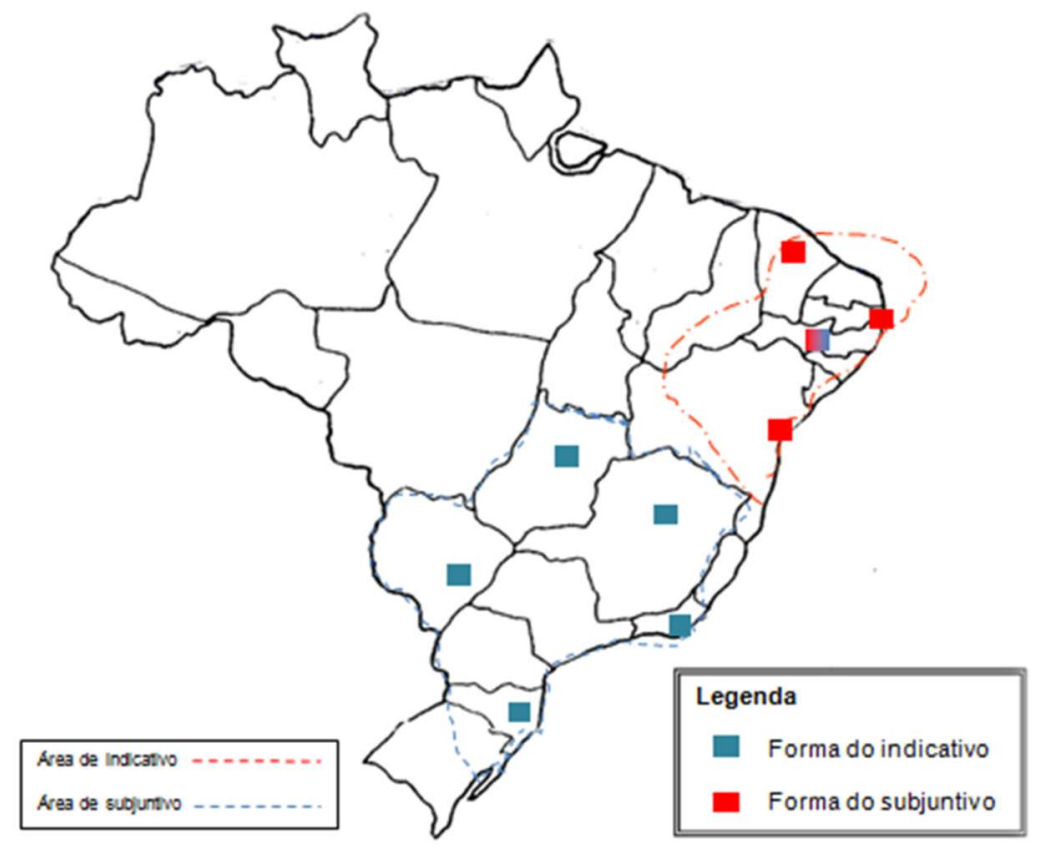

Fonte: Santos (2016, p. 50)

No recorte da variação no português brasileiro, a Bahia, tal qual a maior parte da região Nordeste, revela-se um espaço de prevalência de formas do subjuntivo (SAMPAIO, 2001; OLIVEIRA, 2017). No entanto, há indícios de emprego de formas indicativas em contextos rurais (SANTOS, 2006, 2007; ALVES, 2008).

\section{O UNIVERSO DE OBSERVAÇÃO}

Para contemplar nosso objetivo de ampliar a caracterização e compreensão do português brasileiro no que diz respeito à expressão do modo imperativo,

4 Dados organizados a partir da sistematização apresentada por Scherre (2007, p. 197) e de pesquisas coletadas até 2009. Dados da região Centro-oeste - Brasília (RODRIGUES, 1993; SCHERRE et al., 1998; SILVA, 2003); Goianésia (FERREIRA; ALVES, 2001) e Campo Grande (LIMA, 2005). Dados da região Sudeste - Rio de Janeiro (MORAIS, 1994) (SAMPAIO, 2001); Dados da região Sul - Florianópolis (BONFÁ; PINTO; LUIZ, 1997). Dados da região Nordeste Salvador (SAMPAIO, 2001), Recife (JESUS, 2006), Fortaleza (CARDOSO, 2009), João Pessoa (ALVES, 2001). 
definimos como universo de observação a fala popular de comunidades rurais do estado. Conforme mencionado na introdução, as amostras observadas são formadas pelos dados do acervo de fala do Projeto vertentes do Português popular da Bahia5.

Assim, fazem parte da análise dados de fala de localidades remanescentes de quilombos e comunidades não marcadas etnicamente. No primeiro grupo estão as comunidades geminadas de Barra e Bananal (situadas no município de Rio de Contas); a comunidade de Sapé (em Valença); a comunidade de Cinzento (no município de Planalto); e Helvécia (no extremo sul da Bahia, município de Nova Viçosa). As amostras desse grupo, designadas sob o rótulo de português afro-brasileiro, partilham a origem quilombola e o relativo isolamento social mantido até parte do século XX. As entrevistas de Barra e Bananal e Helvécia foram coletadas no fim do século, as demais foram acrescidas ao conjunto de dados até 2004. O propósito inicial do corpus no âmbito dos estudos morfossintáticos do Projeto Vertentes recobre a tentativa de identificar, no nível morfossintático, vestígios do processo de contato entre línguas que marcou a formação do português.

Entre as comunidades não marcadas, analisamos dados das cidades de Santo Antônio de Jesus (na região do Recôncavo baiano) e Poções (centro sul da Bahia). Esses dados correspondem a segunda etapa de pesquisa do projeto e foram gravadas entre 2002 e 2003. Importante centro comercial e de serviços do Recôncavo Baiano, Santo Antônio de Jesus localiza-se a $200 \mathrm{~km}$ da capital. Os indicadores sociais do município apontam um índice demográfico de 306,99 h/Km² e grau de urbanização 85,62, conforme dados do censo IBGE - 2020, mais próximo à sincronia das entrevistas. Poções, por sua vez, está mais distante da

\footnotetext{
5 O projeto Vertentes (vertentes.ufba.br) está sediado na Universidade Federal da Bahia. Desde 2002, tem se dedicado à coleta, ao tratamento e à análise de aspectos variáveis da morfossintaxe em dados de fala do Português Popular da Bahia, orientado pela tese de que o português popular do Brasil carrega vestígios do contato entre línguas que marcou a formação do país.
} 
capital, cerca de $444 \mathrm{~km}$. Localizado na mesorregião do Centro Sul da Bahia, o município apresenta menores índice de urbanização $(71,93)$ e densidade demográfica $(45,86 \mathrm{~h} / \mathrm{Km} 2)$ se comparados a Santo Antônio de Jesus. Entre as atividades econômicas que caracterizam a cidade estão a produção agrícola e pecuária. O território mantém tradições culturais religiosas e apresentava, no período da coleta dos dados, uma paisagem local pouco modificada pelas intervenções urbanas e um clima de calmaria, com pouca circulação de pessoas, conforme descrevem os informantes entrevistados.

A disposição geográfica das comunidades pode ser observada na Figura 2, a seguir:

Figura 2: Mapa de distribuição das comunidades observadas

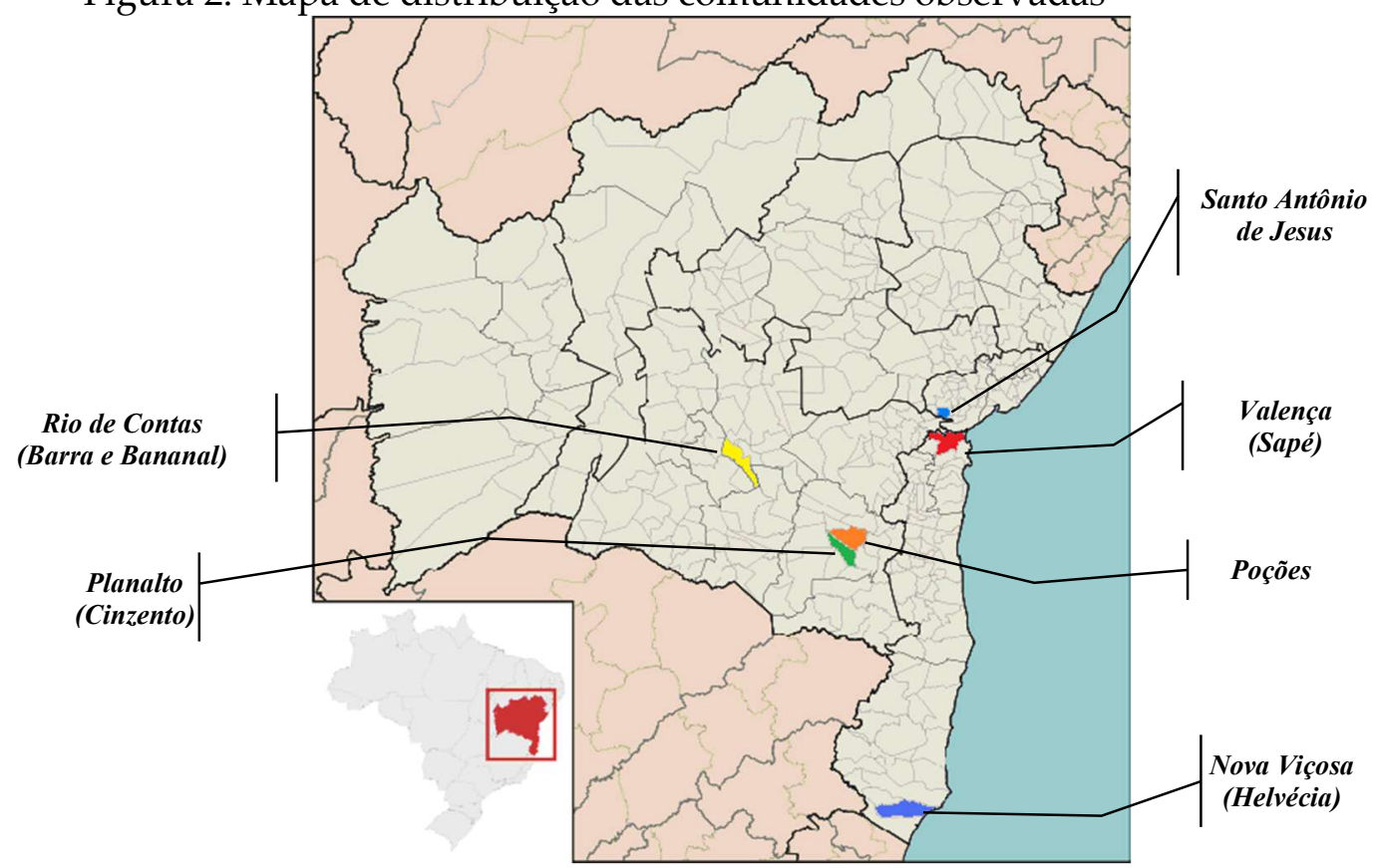

Fonte: Elaborado pela autora com base no site IBGE-cidades.

Para este grupo de dados, foram analisados 109 inquéritos, 48 das comunidades de Santo Antônio de Jesus e Poções e 63 das comunidades etnicamente marcadas. Os informantes que compõem as amostras estão distribuídos conforme as variáveis sexo (masculino/feminino) e faixa etária (Faixa I: de 20 a 40 anos; Faixa II: de 40 a 60 anos; Faixa III: mais de 60 anos e Faixa 
IV: mais de 80 anos). Todos os informantes possuem baixo nível de escolarização, sendo categorizados em dois grupos de variáveis controladas: analfabetos e semialfabetizados. Além disso, para os dados de Santo Antônio de Jesus e Poções, observou-se o período em que os informantes estiveram afastados da comunidade por um período de pelo menos seis meses.

As variantes da nossa variável dependente, formas indicativas (canta) e subjuntivas (cante), foram coletadas exaustivamente nos inquéritos. Cabe pontuar que, após o levantamento das ocorrências, todos os dados foram ouvidos, a fim de atestar que a variante transcrita representava o uso efetivamente empregado pelo informante.

Durante a fase de levantamento, emergiram alguns contextos de neutralização da variação, dentre os quais o emprego de formas cristalizadas (músicas e expressões idiomáticas) e a neutralização vocálica do morfema junto ao elemento subsequente (elisão do morfema modo temporal). Tais dados foram desconsiderados na análise de dados apresentada a seguir.

\section{ANÁLISE DOS DADOS}

Descartados os contextos de cristalização, neutralização, contextos categóricos e marcadores conversacionais, restaram 442 ocorrências. A quantidade de dados reforça a baixa produtividade de imperativo em entrevistas sociolinguísticas tradicionais. Na análise a seguir, são evidenciados os valores gerais da variável dependente (canta $\sim$ cante) e os condicionamentos linguísticos e extralinguísticos investigados. No que se refere às comunidades em estudo, busca-se compreender como se configura a variação do modo imperativo a fim de analisar o padrão predominante, condicionamentos e eventuais relações com o processo de urbanização e o contato entre língua. 
Do cotejo dos dados, evidenciou-se como padrão das comunidades o predomínio das formas associadas ao indicativo, com percentual de 72,9\%, contra 27,1\% das formas subjuntivas, conforme Gráfico 1.

Gráfico 1: Distribuição das variantes do imperativo nas comunidades representativas do português popular rural da Bahia

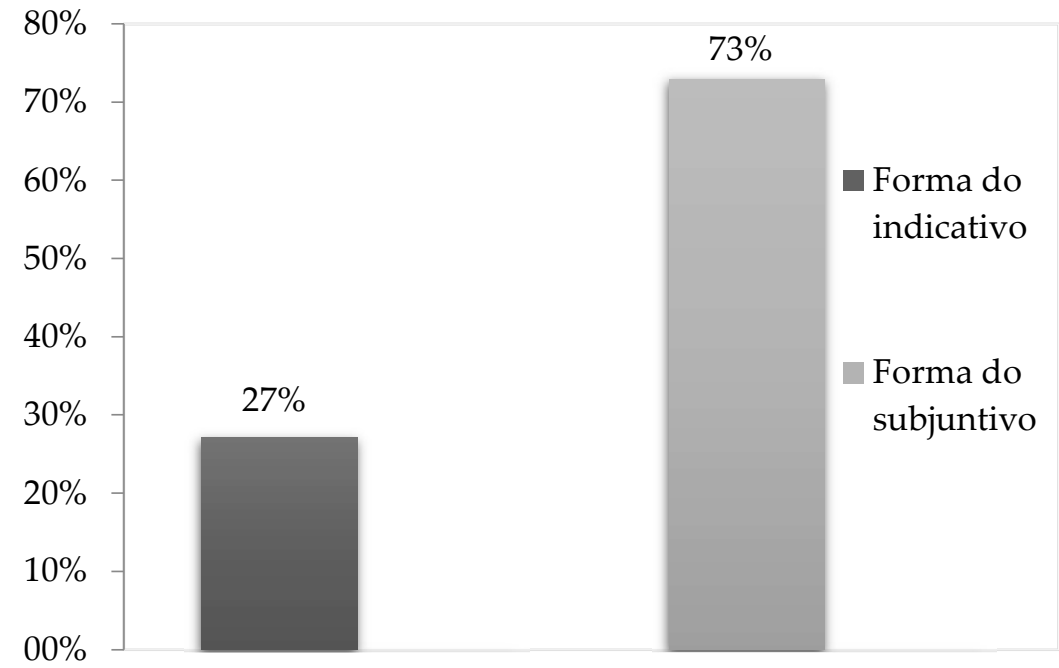

Fonte: Santos (2016, p. 165)

Tal resultado evidencia o contraste entre o paradigma imperativo das comunidades rurais e os padrões de variedades cultas e populares da capital (SAMPAIO, 2001; SANTOS, 2016). O resultado é, portanto, contrário ao paradigma associado ao estado da Bahia e à região Nordeste. No Gráfico 2, compara-se a realização do imperativo nas comunidades rurais da Bahia a resultados encontrados por Santos em falantes de português popular da Capital do Estado (SANTOS, 2016). 
Gráfico 2: A expressão variável do imperativo em amostras do português popular de variedades urbanas e rurais do estado da Bahia

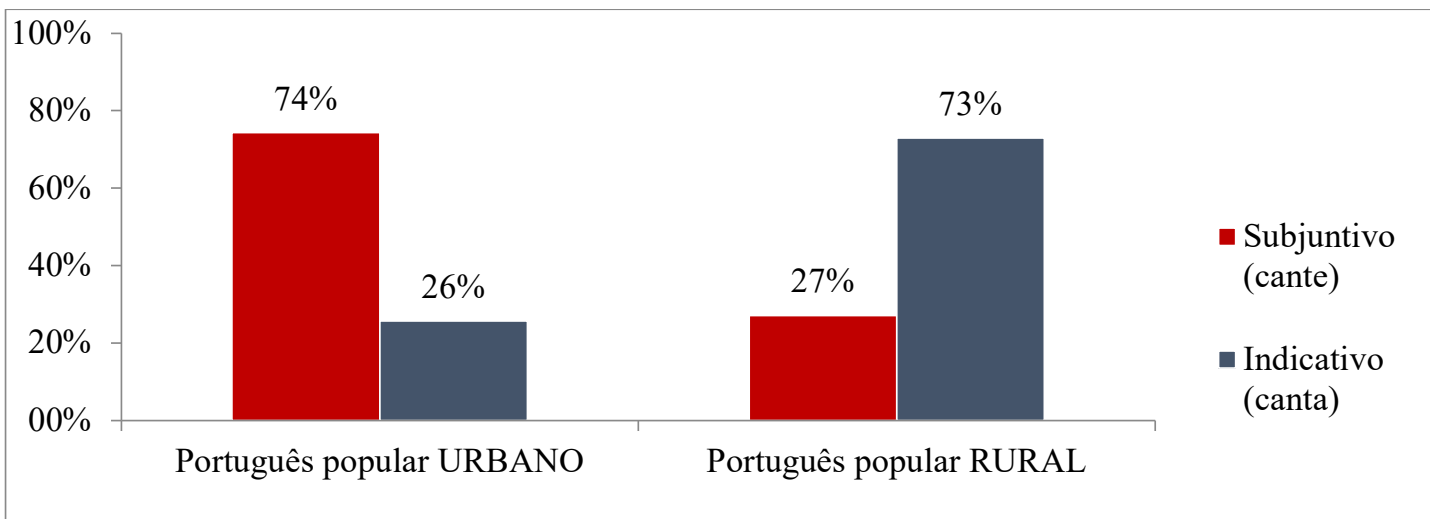

Fonte: Santos (2016, p. 188)

Cabe destacar que o trabalho de Alves (2008) também registrou para a Bahia traços de uma oposição rural-urbano. Ao observar o uso das variantes do imperativo em histórias em quadrinhos (HQ's), o autor encontrou evidências para uma oposição entre os usos rural e urbano do modo imperativo. Foram analisadas duas revistas, "Fala menino", revista de Salvador, e "Turma do Xaxado", revista do município de Jacobina, zona rural da Bahia. Além do contexto representado nas obras (urbano e rural), o local de nascimento dos quadrinistas também foi elemento utilizado para representar a caracterização dialetal.

A fim de compreender o encaixamento da variação do imperativo na Bahia e a natureza do cenário encontrado, apresentamos, a seguir, dados das variáveis explanatórias selecionadas na análise do fenômeno ${ }^{6}$. A princípio, codificamos um extenso grupo de fatores, os quais serviram, além da delimitação de possíveis contextos condicionadores, à tentativa de controlar aspectos qualitativos da amostra e possibilitar a melhor manipulação dos dados. Entre as variáveis

\footnotetext{
6 Os resultados quantitativos do imperativo no português rural da Bahia perfizeram um total de 432 ocorrências. Os dados probabilísticos da rodada alcançaram os seguintes índices: input 0.141; log-likelihood = -217.472; nível de convergência 14; nível de significância 0.042 .
} 
explanatórios linguísticas, definimos grupos de fatores ligados a diferentes dimensões do fenômeno, a saber:

a) verbo: morfologia verbal, paradigma flexional do verbo, paralelismo fônico/conjugação verbal, saliência morfofonológica;

b) sentença: polaridade da estrutura, presença do pronome sujeito, presença do pronome complemento, presença do vocativo;

c) discurso: paralelismo discursivo, pronome empregado com o interlocutor, característica da unidade textual, tipo de interlocutor, gradação semântica, tipo de discurso.

Para fim de identificar o encaixamento social do fenômeno, observamos ainda os aspectos faixa etária, sexo dos informantes, escolaridade e estada fora da comunidade.

Entre fatores linguísticos e sociais, foram selecionados, na ordem em que são expostos a seguir, sete fatores relevantes: paralelismo discursivo, comunidade, pronome utilizado com o interlocutor, escolaridade, polaridade da estrutura, nível de saliência morfofonológica e presença do vocativo. Os resultados seguem exemplificados e comentados nas seções seguintes e foram avaliados pelo GOLDVARB em função da variante inovadora, a forma do subjuntivo (cante).

\subsection{O encaixamento linguístico do fenômeno}

A investigação do encaixamento linguístico do fenômeno apontou, em primeiro lugar, a atuação do paralelismo discursivo. Segundo os resultados quantitativos, o uso de determinada variante na oração anterior favorece a reiteração de uma forma do mesmo tipo na sentença subsequente. Este fator, cuja pertinência tem sido destacada no estudo de outros fenômenos morfossintáticos, mostrou-se relevante nas diferentes análises do modo imperativo observadas. Em nossa análise, o fator cumpriu a sua atuação como princípio linguístico, 
mostrando-se fortemente relevante. Os demais fatores destacados no estudo seguem apresentados e comentados a seguir.

\subsubsection{Pronome utilizado com o interlocutor}

A variável pronome utilizado com o interlocutor visou identificar a forma empregada pelo falante $(t u \sim v o c \hat{e})$ no contexto de realização da ocorrência do imperativo ${ }^{7}$. Os dados encontrados seguem descritos na Tabela 1.

Tabela 1: Uso da variante do subjuntivo com valor imperativo no português popular rural da Bahia, segundo a variável pronome empregado com o interlocutor

\begin{tabular}{cccc} 
Pronome utilizado & № de & Frequência & $\begin{array}{c}\text { Peso } \\
\text { colativo }\end{array}$ \\
oco./TOTAL & $6 / 29$ & $20,7 \%$ & 0.304 \\
Você & $46 / 121$ & $38 \%$ & 0.549 \\
\hline TOTAL & $52 / 150$ & $34,7 \%$ & \\
\hline
\end{tabular}

Fonte: Elaborado pela autora.

De acordo com os resultados da Tabela 1, a forma subjuntiva é favorecida pelo tratamento do interlocutor com o pronome você, frequência $38 \%$ e peso relativo 0.549 . A forma $t u$ desfavorece o emprego do subjuntivo com os valores $20,7 \%$ e peso relativo 0.304 .

Embora a Bahia seja descrita na literatura sociolinguística, com relativa consonância, como uma região em que há predomínio do pronome você, o escrutínio dos estudos aponta a presença ligeiramente maior de emprego do pronome $t u$ fora da capital, como Feira de Santana (NOGUEIRA, 2013), Santo Antonio de Jesus (DIVINO, 2008; 2007; OLIVEIRA, 2007) e comunidades Afrobrasileiras (OLIVEIRA, 2005)․

7 Consideramos o limite de três turnos anteriores e posteriores à sentença.

8 Nos estudos sociolinguísticos sobre o uso do tu e você, são encontradas divergências significativas nos resultados, conforme a metodologia de coleta empregada, gravações consentidas versus gravações secretas. Assim, cabe ponderar que as frequências de $t u$ na língua 
Em nossa leitura, os resultados da variável observada podem ser associados à hipótese de que as formas imperativas do indicativo teriam se fixado primeiro no português rural, juntamente com as formas pronominais $t u$, de amplo emprego; as formas subjuntivas teriam sido introduzidas mais tarde, via influência dos padrões da capital, onde o emprego do você e das formas de subjuntivo é mais expressivo.

\subsubsection{Polaridade da estrutura}

O tipo de frase, afirmativa ou negativa, referido na literatura como polaridade da estrutura (SCHERRE, 2004), foi selecionado entre os fatores condicionantes das realizações do imperativo. Os resultados da variável seguem descritos na Tabela 2:

Tabela 2: Uso da variante do subjuntivo com valor imperativo no português popular rural da Bahia, segundo a variável polaridade da estrutura

\begin{tabular}{cccc}
$\begin{array}{c}\text { Polaridade da } \\
\text { estrutura }\end{array}$ & $\begin{array}{c}\text { No de } \\
\text { oco./TOTAL }\end{array}$ & Frequência & Peso relativo \\
Afirmativo & $93 / 385$ & $24,2 \%$ & 0.475 \\
Negativo & $24 / 47$ & $51,1 \%$ & 0.692 \\
\hline TOTAL & $117 / 432$ & $27,1 \%$ & \\
\hline
\end{tabular}

Fonte: Elaborado pela autora.

Para a análise desse fator, partimos da hipótese de que as formas do subjuntivo seriam favorecidas em contextos de frases negativas. A exemplo do que indicam outros trabalhos sobre o tema (SAMPAIO, 2001; JESUS, 2006 e CARDOSO, 2009), os resultados da nossa análise reforçam a hipótese inicial, uma vez que as frases negativas favoreceram o uso das formas do imperativo derivadas do subjuntivo (cante) com peso relativo 0,692.

falada podem revelar certa imprecisão (PAREDES SILVA, 2003; MODESTO, 2006; DIVINO, 2008). 
Como explicação, aventamos a hipótese de que o efeito prescritivista, que define que as formas negativas são derivadas exclusivamente do modo subjuntivo, mesmo indireto, seria um possível motivador do resultado. Além disso, recorremos ao efeito discursivo sugerido por Sampaio (2001): a possibilidade de leitura ambígua de formas indicativas em contextos negativos "[você] não joga" -, frente à leitura imperativa mais explícita quando na presença de uma forma do subjuntivo - "[você] não jogue". Assim, defendemos que o efeito, ainda que indireto, exercido pela escolarização, bem como a associação mais evidente dessas formas ao valor deôntico se manifestam nos resultados da variável, justificando o condicionamento exercido pela frase negativa sobre a realização do imperativo na variante subjuntiva.

\subsubsection{Nível de Saliência morfofonológica}

A saliência fônica tem sido uma variável associada ao estudo das concordâncias verbal e nominal e define que itens mais salientes, ou seja, com maior distinção morfofonológica entre as formas do singular e plural, tendem a favorecer a aplicação das marcas de concordância (SCHERRE, 1998). Para a adequação da variável ao fenômeno em estudo, partiu-se das asserções de Scherre (2004) sobre o efeito da menor ou maior marcação entre as formas no condicionamento das variantes do imperativo.

menor marcação interna implica tendência de uso do imperativo menos marcado - a variante de tendência mais geral, que é a forma associada ao indicativo; maior marcação interna implica tendência de uso da variante imperativa mais marcada - a variante de tendência menos geral, que é a forma associada ao subjuntivo [...] (SCHERRE, 2004, p. 17)

Assumindo as considerações como hipóteses plausíveis para as comunidades de fala em análise, buscamos definir uma escala de saliência imperativa, por nós constituída, com base nos níveis de diferenciação entre as 
formas variantes, de modo que a definição do nível de saliência seria maior tanto quanto fosse a substancialidade da diferenciação do ponto de vista morfológico.

Quadro 4: Níveis de saliência morfofonológica para a análise do modo imperativo

\begin{tabular}{|c|c|c|}
\hline Níveis & DEFINIÇÃO & EXEMPLO \\
\hline NÍVEL I & $\begin{array}{l}\text { Mudanças apenas no morfema } \\
\text { modo temporal, sem alterações no } \\
\text { radical. }\end{array}$ & $\begin{array}{l}\text { olhalolhe } \\
\text { cumpre/cumpra } \\
\text { esperalespere }\end{array}$ \\
\hline \multirow[t]{2}{*}{ NÍVEL II } & $\begin{array}{l}\text { Alteração no radical em função de } \\
\text { mudanças nos sons consonantais; }\end{array}$ & $\begin{array}{l}\text { ouve/ouça } \\
\text { pede/peça }\end{array}$ \\
\hline & $\begin{array}{l}\text { Alteração no radical em função das } \\
\text { mudanças vocálicas, timbre e } \\
\text { altura de vogal presente no radical. }\end{array}$ & $\begin{array}{l}\text { investe/invista } \\
\text { sobe/suba } \\
\text { serve/sirva } \\
\text { dáldê }\end{array}$ \\
\hline NÍVEL III & Acréscimo de segmento vocálico. & $\begin{array}{l}\text { sai/saia } \\
\text { cai/caia } \\
\text { ri/ria } \\
\text { vai/vá }\end{array}$ \\
\hline
\end{tabular}

Acréscimo de segmento silábico com presença de vogal nasalisada;

NÍVEL IV

Acréscimo de segmento silábico (com inclusão/alteração de som consonantal existente);

vem/venha tem/tenha põe/ponha

Acréscimo de segmento consonatal.

$$
\begin{gathered}
\text { diz/diga } \\
\text { traz/ traga } \\
\text { vê/veja }
\end{gathered}
$$

Fonte: Adaptado de Santos (2016).

Para a análise da variável, partimos da hipótese de que níveis maiores de saliência condicionariam o emprego das formas do subjuntivo, de tendência menos geral e, portanto, mais marcadas nos usos das comunidades. Os resultados da variável seguem dispostos na Tabela 3. 
Tabela 3: Uso da variante do subjuntivo com valor imperativo no português popular rural da Bahia, segundo a variável saliência morfofonológica

\begin{tabular}{cccc}
$\begin{array}{c}\text { Saliência } \\
\text { morfofonológica }\end{array}$ & № de oco./TOTAL & Frequência & $\begin{array}{c}\text { Peso } \\
\text { relativo }\end{array}$ \\
Nível 1 & $48 / 206$ & $23,3 \%$ & 0.478 \\
Nível 2 & $8 / 60$ & $13,3 \%$ & 0.328 \\
Nível 3 & $40 / 90$ & $44,4 \%$ & 0.649 \\
Nível 4 & $21 / 76$ & $27,6 \%$ & 0.519 \\
\hline TOTAL & $117 / 432$ & $21,7 \%$ &
\end{tabular}

Fonte: Elaborado pela autora.

O índice de frequência de $44 \%$ e peso relativo 0.649 indicou o Nível III como o mais favorável à realização da forma marcada do subjuntivo. O Nível II desfavorece as formas em análise com peso relativo 0.328. Os níveis I e IV alcançaram índices muito próximos à neutralidade, com pesos relativos $0.478 \mathrm{e}$ 0.519, respectivamente. Os resultados, portanto, embora indiquem alguma relevância da saliência morfofonológica, sobretudo entre os níveis 2 e 3, são pouco conclusivos em relação aos demais níveis, o que pode estar relacionado aos critérios de delimitação da variável, ao tratamento estatístico aplicado ou à influência do comportamento dos verbos em particular, uma vez que alguns tendem a ser mais produtivos no uso do imperativo que outros.

\subsubsection{Presença do vocativo}

O vocativo, elemento importante e recorrente nas sentenças imperativas, desempenha o papel de direcionar o comando expresso ao interlocutor. Segundo Scherre (2004), a evocação do interlocutor por meio do vocativo funciona no sentido de assegurar a leitura imperativa da sentença. Partimos, para a análise desta variável, dos valores exemplificados em (3) e (4):

(3) Presença do vocativo: Ô menino, volta, pelo amor de Deus! (POR-07)

(4) Ausência do vocativo: num bole em minha perna não (POR-08) 
O subjuntivo depende menos de reforço contextual para garantir a interpretação imperativa, enquanto a forma do indicativo, por possibilitar uma leitura ambígua em algumas situações, necessita de um reforço discursivo, nesse caso, o vocativo. A hipótese orientadora desta análise centra-se, portanto, na definição de que a presença do vocativo seria mais significativa para o uso das formas do indicativo, haja vista as razões discursivas já descritas. Por oposição, as formas em relevo nesta análise, subjuntivas (cante), seriam desfavorecidas na presença do vocativo e, consequentemente, favorecidas em sua ausência.

Tabela 4: Uso da variante do subjuntivo com valor imperativo no português popular rural da Bahia, segundo a variável presença do vocativo

\begin{tabular}{cccc} 
Vocativo & $\begin{array}{c}\text { No de } \\
\text { oco./TOTAL }\end{array}$ & Frequência & $\begin{array}{c}\text { Peso } \\
\text { relativo }\end{array}$ \\
Presença & $24 / 113$ & $21,2 \%$ & 0.390 \\
Ausência & $95 / 319$ & $29,7 \%$ & 0.540 \\
\hline TOTAL & $117 / 432$ & $27,1 \%$ & \\
\hline
\end{tabular}

Fonte: Elaborado pela autora.

Os resultados da Tabela 4 apontam conformidade com a hipótese proposta: a presença do vocativo desfavorece o emprego da variante do subjuntivo com peso relativo 0.390 e frequência $21,2 \%$. É importante ressaltar que o efeito desfavorecedor desse fator parece ser mais expressivo do que o efeito da ausência do vocativo, uma vez que o peso relativo 0.540 mostrou-se relativamente próximo ao índice de neutralidade 0.500 .

\subsection{O encaixamento social do fenômeno}

Do conjunto inicial de seis variáveis sociais, foram selecionados pelo Goldvarb dois grupos de fatores: escolaridade e comunidade de fala do informante. 


\subsubsection{Escolaridade}

Em nosso trabalho, distinguem-se dois níveis de escolaridade, analfabetos e semialfabetizados. Nossa opção por níveis baixos é coerente com a dedicação à compreensão do português popular da Bahia, cuja caracterização engloba, sobremaneira, o precário acesso à escolarização.

Consideramos o efeito da normatização linguística no sentido de associar o uso das formas derivadas do subjuntivo para o tratamento do interlocutor com o pronome você. Assim, defende-se a hipótese de que o contato com o processo de escolarização, ainda que incipiente, favorece o emprego das formas subjuntivas na amostra observada.

Os resultados dessa variável seguem descritos na Tabela 5:

Tabela 5: Uso da variante do subjuntivo com valor imperativo no português popular rural da Bahia, segundo a variável escolaridade

\begin{tabular}{lccc} 
Escolaridade & $\begin{array}{c}\text { № de } \\
\text { oco./TOTAL }\end{array}$ & Frequência & $\begin{array}{c}\text { Peso } \\
\text { relativo }\end{array}$ \\
Semialfabetizados & $67 / 186$ & $36 \%$ & 0.611 \\
Analfabeto & $50 / 246$ & $20,3 \%$ & 0.416 \\
\hline TOTAL & $117 / 432$ & $27,1 \%$ & \\
\hline
\end{tabular}

Fonte: Elaborado pela autora.

Os resultados da Tabela 5 confirmam a hipótese de trabalho. Os dados de falantes semialfabetizados favorecem o emprego das formas inovadoras do subjuntivo (cante) com frequência 36\% e peso relativo 0.611 . Os falantes que não frequentaram a escola e não receberam qualquer tipo de instrução formal desfavorecem a aplicação das variantes do subjuntivo com frequência 20,3\% e peso relativo 0.416 . 


\subsubsection{Comunidade}

Esperávamos, com esta variável, identificar os efeitos da constituição histórica das localidades analisadas, sobretudo a relevância do contato entre línguas na variação das formas imperativas. Aventamos ainda a hipótese de que o vetor de urbanização e relação das comunidades com a capital do estado exerçam alguma influência no comportamento fenômeno. Os resultados da variável seguem descritos na Tabela 6.

Tabela 6: Uso da variante do subjuntivo com valor imperativo no português popular rural da Bahia, segundo a variável comunidade de fala

\begin{tabular}{lccc} 
Comunidade de fala & № de oco./TOTAL & Frequência & $\begin{array}{c}\text { Peso } \\
\text { relativo }\end{array}$ \\
Poções & $25 / 136$ & $18,4 \%$ & 0.377 \\
Santo Antônio de & $60 / 140$ & $42,9 \%$ & 0.657 \\
Jesus & $10 / 44$ & $22,7 \%$ & 0.533 \\
Helvécia & $4 / 42$ & $9,5 \%$ & 0.277 \\
Cinzento & $2 / 24$ & $8,3 \%$ & 0.244 \\
Rio de Contas & $16 / 46$ & 34,8 & 0.700 \\
Sapé & $117 / 432$ & $27,1 \%$ & \\
\hline TOTAL & &
\end{tabular}

Fonte: Elaborado pela autora.

Os dados quantificados pelo programa Goldvarb demonstram, conforme esperado, o predomínio das formas indicativas em todas as comunidades, reforçando a hipótese de que tal padrão representa parte da realidade rural da Bahia. Considerando que o português popular do estado pode guardar traços do contato entre língua, tais como a perda da morfologia flexional, a prevalência das formas indicativas para expressão do imperativo pode ser indicativa desse processo. Como reforço de nossa hipótese, cabe destacar que, entre algumas línguas crioulas, a expressão do imperativo é marcada pelo emprego exclusivo da forma base não flexionada, diretamente negada, como acontece no Lung'Ie, 
(AGOSTINHO, 2015), no Paiamento (GOILO, 1993), e no Crioulo Caboverdiano (QUINT, 2000; 2003).

Esperávamos que as comunidades afro-brasileiras, mais marcadas pelo contato massivo entre línguas, apresentassem índices maiores de formas imperativas derivadas do modo indicativo (canta), em detrimento das comunidades de Santo Antônio de Jesus e Poções, que se comprovou parcialmente.

Santo Antônio de Jesus além de mais próxima da capital apresenta indicadores sociais (população, densidade demográfica e grau de urbanização) mais expressivos que Poções. Assim, podemos considerar uma possível relação entre os padrões de imperativo empregados, o grau de desenvolvimento urbano dos municípios e a relação com a capital.

No que diz respeito ao comportamento linguístico das comunidades afrobrasileiras, embora todas as localidades tenham contabilizado níveis de frequência de formas imperativas associadas ao indicativo acima de $65 \%$, a comunidade de Sapé mostrou-se um contexto favorável ao emprego da variante do subjuntivo, com peso relativo 0,700 e frequência 34,8\%. A comunidade de Helvécia, com peso 0,533 e frequência 22,7\%, mostrou-se próxima ao nível de neutralidade. Como desfavorecedoras, destacaram-se as comunidades de Cinzento $(0,277)$ e Rio de Contas $(0,244)$. Aspectos particulares que caracterizam as comunidades podem estar relacionados aos resultados.

A comunidade de Sapé, situada no município de Valença, é, entre as comunidades afro-brasileiras, a mais próxima da capital do estado, Salvador (123 $\mathrm{km}$ ), estando ainda a apenas 77,1 km de Santo Antônio de Jesus. O contato dialetal com o entorno pode estar sobrepondo-se ao efeito pretérito de aquisição das formas base do indicativo e motivando o incremento das formas do subjuntivo. 
Considerando os argumentos sociodemográficos levantados para a oposição entre os municípios de Santo Antônio de Jesus e Poções e o caráter particular de localização em que se insere Sapé, podemos concluir que, para além do contato entre língua, deve ser considerada a relevância da urbanização na dialetação do imperativo na Bahia. Dessa forma, as regiões mais próximas de Salvador podem estar recebendo os efeitos de sua região de influência, conforme acontece com Santo Antônio de Jesus, mais sensível que as demais comunidades às formas subjuntivas. A relativa proximidade dessa comunidade ao centro metropolitano do estado, Salvador, e a recepção direta de suas influências favoreceriam a incorporação das variantes de subjuntivo.

Cabe a ponderação de que a distribuição dos dados entre as diferentes comunidades deve ser levada em consideração.

\section{CONSIDERAÇÕES FINAIS}

O presente capítulo buscou identificar, a partir da análise de amostras de fala do interior do estado da Bahia, os padrões de emprego do modo imperativo no que tange ao uso das variantes indicativa (canta) ou subjuntiva (cante) e seu encaixamento linguístico e social. Nossa abordagem aliou a necessidade de se ampliar o conhecimento sobre o fenômeno ao objetivo central deste trabalho, a compreensão do processo de aquisição e difusão do imperativo na Bahia e sua relação com a constituição sócio histórica do português popular do Brasil, particularmente o efeito do contato entre línguas. A Figura 5 esquematiza as principais evidências linguísticas e sócio históricas levantadas. 
Figura 5: Origens e evidências sobre a expressão imperativo nas comunidades rurais da Bahia

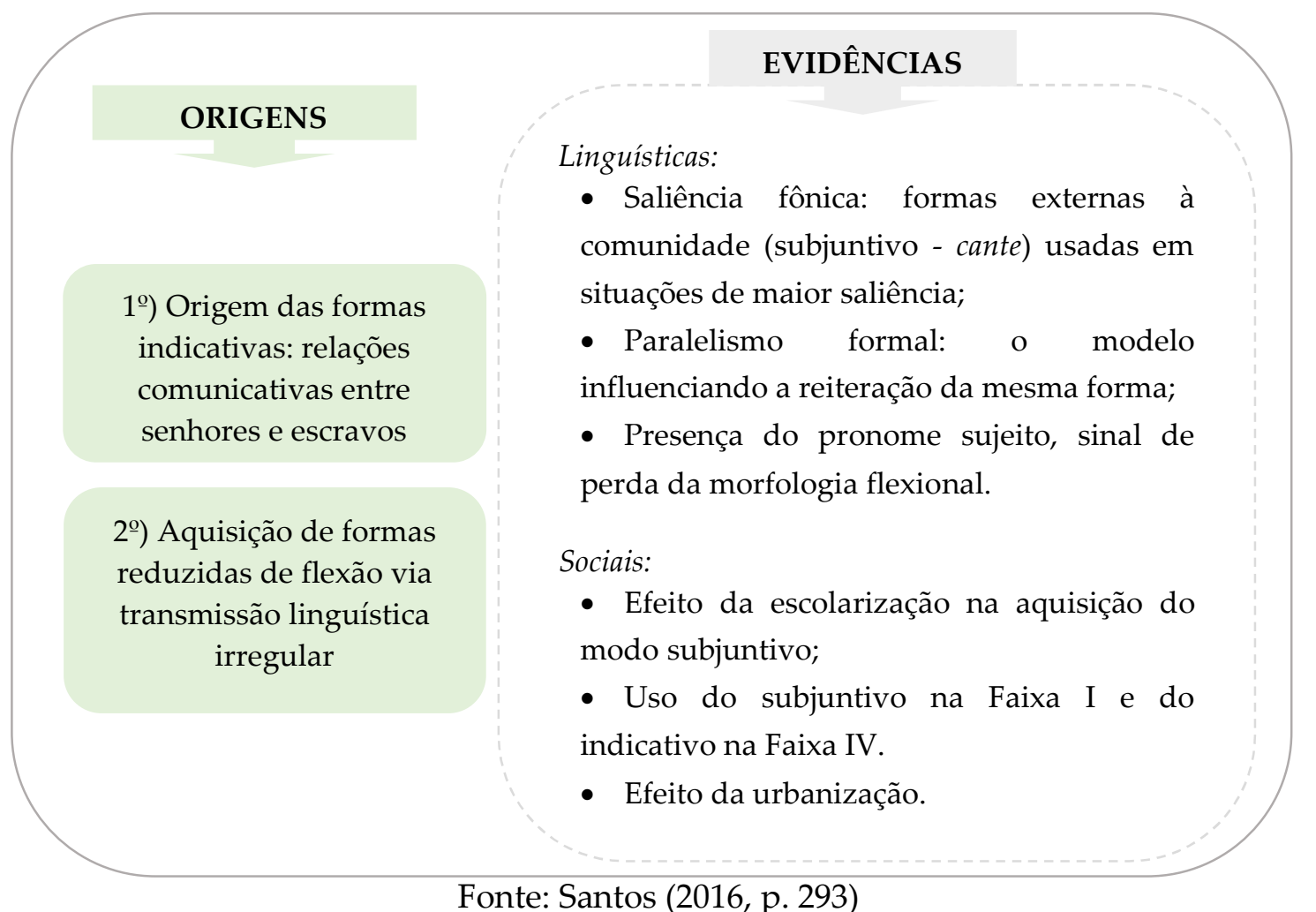

Fonte: Santos (2016, p. 293)

Em linhas gerais, podemos inferir que, nas comunidades rurais, ao lado de uma forma menos flexionada (a variante do indicativo - canta), possivelmente adquirida sob efeito do contato linguístico, está sendo introduzida a variante subjuntiva a partir dos mais jovens, mais escolarizados e pela influência da urbanização. Ademais, as variantes subjuntivas tendem a ser favorecidas em contextos de maior saliência morfofonológica, o que sugere uma leitura das formas como inovadoras nas comunidades. A relação com a forma pronominal você e a polaridade negativa, aspectos consagrados por outros estudos como condicionamentos importantes do imperativo, também foram destacados no encaixamento linguístico do fenômeno como condicionamentos relevantes.

Temos ciência de que, embora tratemos um conjunto relativamente diversificado e amplo de comunidades, as amostras não dão conta da diversidade social e cultural do extenso território baiano. Assim, o trabalho não é capaz de 
encerrar a descrição da realização do imperativo em comunidades rurais da Bahia, antes demarca uma oposição entre variedades rurais e urbanas do estado que pode e deve ser estendida e confrontada com a realidade de outras regiões do território.

\section{REFERÊNCIAS}

AGOSTINHO, Ana Lívia dos Santos. Fonologia e método pedagógico do Lung'Ie. 2015. 425 f. Tese (Doutorado em Filologia e Língua Portuguesa) - Universidade de São Paulo, São Paulo, 2015.

ALVES, Gilson Chicon. Aspectos do uso do imperativo na linguagem oral do pessoense. 2001. 96 f. Dissertação (Mestrado em Letras) - Universidade Federal da Paraíba, João Pessoa, 2001.

ALVES, Jeferson da Silva. O imperativo singular em histórias em quadrinhos baianas. Revista eletrônica de divulgação científica em Língua Portuguesa, Linguística e Literatura, ano 4, n. 9, p. 1-18, 2008. Disponível em <http://www.letramagna.com/imperativohq.pdf>. Acesso em 20 set. 2020.

BECHARA, Evanildo. Moderna Gramática Portuguesa. 37. ed. Rio de Janeiro: Lucerna, 2002.

BONFÁ, C. R.; PINTO, I. A.; LUIZ, I. Imperativo: uma comparação entre Lages e Florianópolis. Florianópolis: Universidade Federal de Santa Catarina/CEP, 1997. (Série de Estudos Diacrônicos).

BORTONI-RICARDO, Stella Maris. Do campo para a cidade: estudo sociolingüístico de migração e de redes sociais. São Paulo: Parábola Editorial, 2011.

BORTONI-RICARDO, Stella Maris. Educação em língua materna: a sociolingüística na sala de aula. São Paulo: Parábola, 2006.

CARDOSO, Daisy Barbara Borges. Variação e mudança no imperativo no português brasileiro: gênero e identidade. 2009. 153 f. Tese (Doutorado em Linguística) Universidade Federal de Brasília, Brasília, 2009.

CASTILHO, Ataliba Teixeira de. Nova gramática do Português Brasileiro. São Paulo: Contexto, 2010.

CUNHA, Celso; CINTRA, Lindley. Nova Gramática do português contemporâneo. 17. ed. Lisboa: Jõao Sá da Costa, 2002.

FERREIRA, Graziele de Lourdes Novato. Cinzento: memória de uma comunidade negra remanescente de quilombo. 1999. 176 f. Dissertação (Mestrado em História) - Pontifícia Universidade Católica de São Paulo, São Paulo, 1999.

GOILO, Enrique. Gramatica papiamentu. Curaçao: Hollandsche Boekhandel, 1953. 
JESUS, Étel Teixeira de. O Nordeste na mídia e os estereótipos linguísticos: estudo do imperativo na novela Senhora do destino. 2006. 144 f. Dissertação (Mestrado em Letras) Universidade de Brasília, Brasília, 2006.

IBGE. Região de influência das cidades 2007. Rio de Janeiro: IBGE, 2008.

IBGE. Censos demográficos. Rio de Janeiro: IBGE, 2010a. Disponível em: $<$ http://biblioteca.ibge.gov.br/>. Acesso em 15 out. 2015.

LABOV, William. Padrões Sociolingüísticos. Tradução Marcos Bagno, Maria Marta Scherre e Caroline Rodrigues Cardoso. São Paulo: Parábola, 2008 [1972].

LIMA, Damaris Pereira Santana. O uso do modo imperativo na fala de Campo Grande - Mato Grosso do Sul. Dissertação (Mestrado em Letras). Brasília/Campo Grande: UnB/UNIDERP, 2005.

LUCCHESI, Dante; BAXTER, Alan; SILVA, Jorge Augusto Alves da; FIGUEIREDO, Cristina. O português afro-brasileiro: as comunidades analisadas. In: LUCCHESI, Dante; RIBEIRO, Ilza. (org.). O português afro-brasileiro. Salvador: EDUFBA, 2009. p. 75-100.

MODESTO, Artarxerxes Tiago Tacito. Formas de tratamento no português brasileiro: a alternância tu e você na cidade de Santos-SP. 2006. 144 f. Dissertação (Mestrado em Letras) - Faculdade de Filosofia, Letras e Ciências Humanas, Universidade de São Paulo: São Paulo, 2006.

MORAIS, R. D. O uso e emprego dos imperativos 2. Brasília: UnB, 1994.

NOGUEIRA, Francieli Motta. Como os falantes de Feira de Santana e Salvador tratam seu interlocutor? 2013. 136 f. 135f. Dissertação (Mestrado em Letras) - Universidade Federal da Bahia, Salvador, 2013

OLIVEIRA JR., Miguel. Aspectos técnicos na coleta de dados linguísticos orais. In: FREITAG, Raquel Meister Ko. (org.). Metodologia de Coleta e Manipulação de Dados em Sociolinguística, São Paulo: Edgard Blücher, 2014. p. 19-26.

OLIVEIRA, Josane Moreira de; "O imperativo gramatical nas capitais do Nordeste: análise sociolinguística de dados do ALiB", p. 27 -44. In: Estudos sobre o Português do Nordeste: língua, lugar e sociedade. São Paulo: Blucher, 2017.

OLIVEIRA, Luanda Almeida Figueiredo de. Tu e você no português afro-brasileiro. Comunicação ao VI Seminário de Pesquisa e Pós-Graduação da UFBA. Salvador, 2005.

OLIVEIRA, Luanda Almeida Figueiredo de. Tu e Você no português popular do estado da Bahia. Comunicação ao VIII Seminário de Pesquisa e Pós-Graduação da UFBA. Salvador, 2007.

PAREDES SILVA, Vera Lúcia. O retorno do pronome tu à fala carioca. In: RONCARATI, Cláudia; ABRAÇADO, Jussara. (org.). Português brasileiro: contato lingüístico, heterogeneidade, história. Rio de Janeiro: 7 Letras, 2003. p. 160-169.

QUINT, Nicolas. Grammaire de La langue cap-verdienne: étude descriptive el compréhensive du créole afro-portugais dês Íles du cap-vert. Paris: L'Harmattan, 2000.

ROCHA LIMA, Carlos Henrique da. Gramática normativa da língua portuguesa. 42. ed. Rio de janeiro: José Olympio, 2003. 
RODRIGUES, M. da S. Estudo da formação do imperativo na linguagem oral e escrita. Brasília: UnB, 1993.

SAMPAIO, Theodoro; TESCHAUER, Carlos. Os naturalistas viajantes dos séculos XVIII e XIX e o progresso da etnografia indígena no Brasil. Salvador: Livraria Progresso, 1955.

SANTOS, Lanuza Lima. O uso do imperativo no português afro-brasileiro. [s.l.]: [s.n.]. 2006. In: XXV Seminário Estudantil de Pesquisa - SEMEP, Salvador, 2006. Comunicação oral... Salvador: Universidade Federal da Bahia, 2006.

SANTOS, Lanuza Lima. O uso do modo imperativo no português rural do estado da Bahia. In: VIII Seminário de Pesquisa e Pós-Graduação da UFBA. Salvador, 2007. Comunicação oral... Salvador: Universidade Federal da Bahia, 2007.

SANTOS, Lanuza Lima. FALA (VOCÊ/TU) FALE (VOCÊ/TU): a expressão variável do modo imperativo no português popular da Bahia. 2016. 319 f. Tese (Doutorado em Língua e Cultura) - Universidade Federal da Bahia, 2016.

SCHERRE, Maria Marta Pereira. Norma e uso: o imperativo no português brasileiro. In: DIETRICH, W.; NOLL, V. (org.). O português do Brasil: perspectivas da pesquisa atual. Madrid: Iberoamericana, 2004. p. 231-260.

SCHERRE, Maria Marta Pereira. Aspectos sincrônicos e diacrônicos do imperativo gramatical no português brasileiro. Alfa, São Paulo, v. 51, n. 1, p. 189-222, 2007.

SCHERRE, Maria Marta Pereira et alii. Reflexões sobre o imperativo em português. D.E.L.T.A., v. 23, 2007, p. 193-241.

SCHERRE, Maria Marta Pereira et al. Phonic Paralelism: evidence from the imperative in Brazilian Portuguese. In: PARADIS, C. et al. (org.). Papers in sociolinguistics. NWAVE-26 à l'Université Laval. Québec: Nota Bene, 1998. p. 63-72.

SILVA, C. A. da. O imperativo na língua falada da região centro-oeste. Brasília: UNIP, 2003.

WEINREICH, Uriel; LABOV, William; HERZOG, Marvin. Fundamentos empíricos para uma teoria da mudança lingüística. Tradução Marcos Bagno. São Paulo: Parábola, 2006 [1968].

\section{A AUTORA E O PPGLinC}

\section{Lanuza Lima Santos}

Bacharel e licenciada em Letras Vernáculas pela Universidade Federal da Bahia (UFBA), Mestre em Letras e Linguística e Doutora em Língua e Cultura também pela UFBA. Vinculada ao Grupo de Pesquisa Vertentes do Português Popular do Estado da Bahia, desenvolve, desde a graduação, pesquisa na área de sociolinguística, mais especificamente sobre aspectos variáveis da morfossintaxe 
do português popular da Bahia. Atualmente, é professora EBTT do Instituto Federal de Educação Ciência e Tecnologia da Bahia (IFBA), líder do Grupo de Pesquisa Mosaico, centrado no estudo sobre variação, ensino e tecnologia, e coordena o Projeto de Extensão "Poeme-se: revista de divulgação literária do IFBA Campus Camaçari".

Nota do editor:

Artigo submetido para avaliação em: 04 de outubro de 2020.

Aprovado em sistema duplo cego em: 27 de janeiro de 2021. 